\title{
SURVEILLANCE OF MORTALITY: FROM A TERTIARY CARE TEACHING HOSPITAL OF EASTERN INDIA IN PERSONS WITH AND WITHOUT DIABETES MELLITUS
}

\author{
SHOBHITENDU KABI ${ }^{1}$, SHRIKANT KUMAR DHAR ${ }^{1}$, BAIKUNTHA NATH PANDA ${ }^{1}$, CHANDAN DAS ${ }^{1}$, \\ KAMAL KANT JENA ${ }^{1}$, MAHESH CHANDRA SAHU ${ }^{2 *}$
}

${ }^{1}$ Department of Medicine, IMS and SUM Hospital, Siksha '0' Anusandhan University, Bhubaneswar 751 003, Odisha, India. ${ }^{2}$ Directorate of Medical Research, IMS and SUM Hospital, Siksha ‘O’ Anusandhan University, Bhubaneswar 751 003, Odisha, India. Email: mchsahu@gmail.com

Received: 01 February 2017, Revised and Accepted: 09 March 2017

ABSTRACT

Objective: There is abundant knowledge about the gravity of global load of diabetes mellitus (DM). There are conflicting reports on the cause of death from different parts of the world. In India, there are not enough studies to establish the cause of death in DM. To find out the mortality pattern in DM and non-DM (NDM) in a tertiary care teaching hospital in Eastern India.

Methods: Retrospective analysis of in-hospital mortality in a tertiary care hospital in Eastern India, from January 2012 to December 2015.

Results: There were a total of 1590 deaths of which 442 were having DM and 1148 did not have DM (NDM). Mean age of death for nondiabetics was 66.4 years $(\mathrm{M}: \mathrm{F}=67.5: 65.3)$ and that for diabetics were 62.7 years $(\mathrm{M}: \mathrm{F}=63.5: 60.04)$ which was not statistically significant $(\mathrm{p}=0.9)$ though diabetics died younger by 4 years. On analyzing the specific cause of death, coronary artery disease (CAD) was $14.71 \%$ in DM and $1.57 \%$ in NDM (p=0.0001). Chronic kidney disease (CKD) was $18.55 \%$ in DM and $1.92 \%$ in NDM ( $\mathrm{p}=0.0001)$. Congestive heart failure was $7.27 \%$ in DM and $1.83 \%$ in NDM $(p=0.0001)$. CVA was $13.57 \%$ in DM and $1.66 \%$ in NDM ( $p=0.0001)$. Infection was the most common cause of death (39.37\%) in DM, but in NDM also this was quite high $34.41 \%(\mathrm{p}=0.21)$. The death due to CVA in DM was more in hemorrhage as compared to ischemic ( $\mathrm{p}=0.00001)$.

Conclusion: We found causes of death in DM were an infection, CKD, CAD, CVA, and CHF in descending order in this part of the world. The diabetes patients had lesser hospital stay than nondiabetes patients ( $\mathrm{p}=0.009)$.

Keywords: Diabetes mellitus, Infection, Morbidity, Mortality.

(C) 2017 The Authors. Published by Innovare Academic Sciences Pvt Ltd. This is an open access article under the CC BY license (http://creativecommons. org/licenses/by/4. 0/) DOI: http://dx.doi.org/10.22159/ajpcr.2017.v10i6.17430

\section{INTRODUCTION}

Diabetes mellitus (DM) is the leading cause of morbidity and mortality in India [1,2]. A recent national survey of diabetes conducted in six major cities in India: New Delhi, Chennai, Bangalore, Hyderabad, Kolkata, and Mumbai gave a prevalence of diabetes and impaired glucose tolerance in urban adults of $12.1 \%$ and $14.0 \%$, respectively [1]. According to the World Health Organization estimates, India had nearly 19.4 million adults with diabetes in 1995 and is projected to have 57.2 million by 2025 [3]. Of the estimated 25 million persons with diabetes in India in 1999, only 3.6 million received pharmacological treatment [4]. The Bangalore Urban Diabetes Study estimated that the annual direct cost for diabetes care in 1998 was about US\$191, and the mean direct cost per hospitalization for a diabetes-related event was about US\$ 208 [5]. The per capita expenditure on health care in India is only $6.4 \%$ of the average world spending on health, while India accounts for $23.5 \%$ of the world's disability-adjusted life years lost due to diabetes [6]. Epidemiologic studies on mortality in DM in the Western countries and Japan showed that cardiovascular and cerebrovascular diseases are the leading causes of death [7-14], while no such information is available from India and other developing countries. A few earlier hospital based reports from India had reported infection and chronic renal failure as the leading causes of death in hospitalized patients $[15,16]$. Due to scant information on mortality in diabetes from this part of the world where the prevalence of diabetes is higher, we collected and analyzed data from our hospital records over a 4 years period.

\section{METHODS}

In this retrospective study, all the information was collected from inpatients' medical records at IMS and SUM Hospital, Bhubaneswar,
India, from January 2012 to December 2015 and rerecorded in a structured format. This study is approved from our Institutional Ethics Committee. SUM Hospital is a large multidisciplinary teaching hospital in Eastern India with over 1 million outpatients, and 1,65,388 were admitted during the study period. All death case files (1590) were retrieved. Each file was scrutinized for confirmation of the diagnosis of DM and its reason(s) for admission and secondary/tertiary disease or diabetes related complications contributing to death [17]. Data collected were age, sex, blood glucose at presentation, evidence of micro- and macrovascular complications, concurrent illness and time in hospital preceding death. Cause of death was evaluated with respect to (1) presence of diabetes-related complications and (2) associated illnesses. Some patients died of diseases unrelated to diabetes such as malignancy (other than carcinoma pancreas), gastrointestinal bleeding, and hepatic failure/cirrhosis. These were classified as diabetes unrelated deaths. The cause of death (single or multiple) was compared with nondiabetic patients died during this period.

\section{Statistical analysis}

The Statistical Program for the Social Sciences, version 7.5, PC Windows package was used for data analysis. In addition to descriptive statistics, the $\chi^{2}$-test was used to assess the association between categorical variables and t-test for comparison among continuous variables. Twotailed p values were calculated, and PB/0.05 was taken as statistically significant.

\section{RESULT}

In this 4-year retrospective study, it was revealed that 1590 adult patients died in this hospital out of total 1,65,388 adult admissions. 
Out of 1590 deaths, 442 patients had diabetes and rest did not have diabetes. A t-test was analyzed between the patients died with diabetes and without diabetes and found not significant as it is equally distributed in both groups $(\mathrm{p}=0.9$, Table 1$)$. It was observed that the death of patients in both diabetes and nondiabetes groups were on increasing order according to increasing age (Fig. 1).

All patients died with diabetes were classified it into two groups, i.e., with diabetes-related disease (DRD) (377 patients) and diabetes non-related diseases (DNRD) (65 patients). From t-test, it was revealed that it is highly significant ( $p=0.02$ ). Hence, the patients with diabetes have much higher chance of death if they have DRD compared to those with DNRD in the same age groups (Table 2). The diabetes patients with diabetes complications had much higher chance of death compared to those with non DRD in all the age group (Fig. 2).

We also tried to check for any significant difference in sex for NDM as far as mortality for a particular complication is concerned. However, we found all the complications leading to death were equitably distributed in both sexes expect infection. In the case of infection, M: F was 117:53 which was statistically significant at $\mathrm{p}=0.03$ (Table 3 ).

Our study revealed that the diabetes patients with more complications had more chance of death compared to those having less complication. We had $17.87 \%$ deaths with one complication, $35.29 \%$ deaths with two complications and $46.83 \%$ with three or more complications. The hospital stay before death also diminishes as the number of complications increased (Table 4).

There were 1148 deaths without diabetes, with a mean age at death 66.4 years (M:F - 67.5:65.3). Contributory factors were infections - $34.39 \%$ (average age 69.2 years), stroke - 1.66\% (average

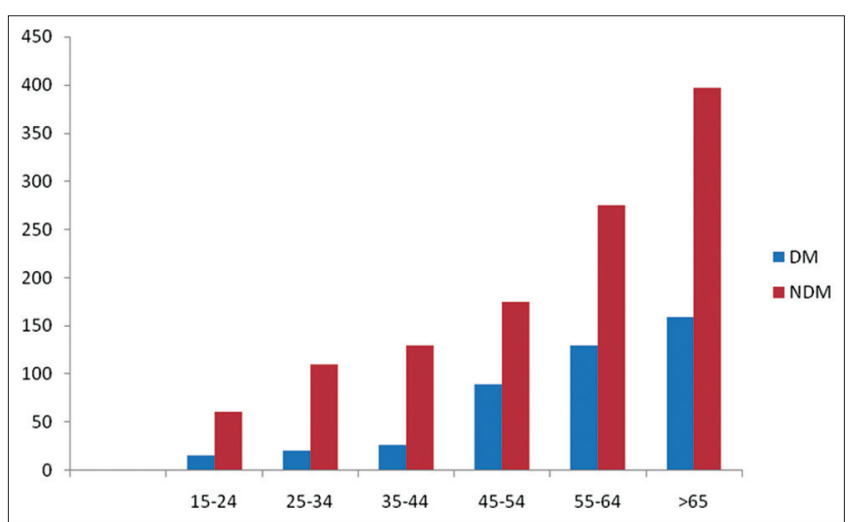

Fig. 1: Bar diagram of death of patients with diabetes and nondiabetes according to age group

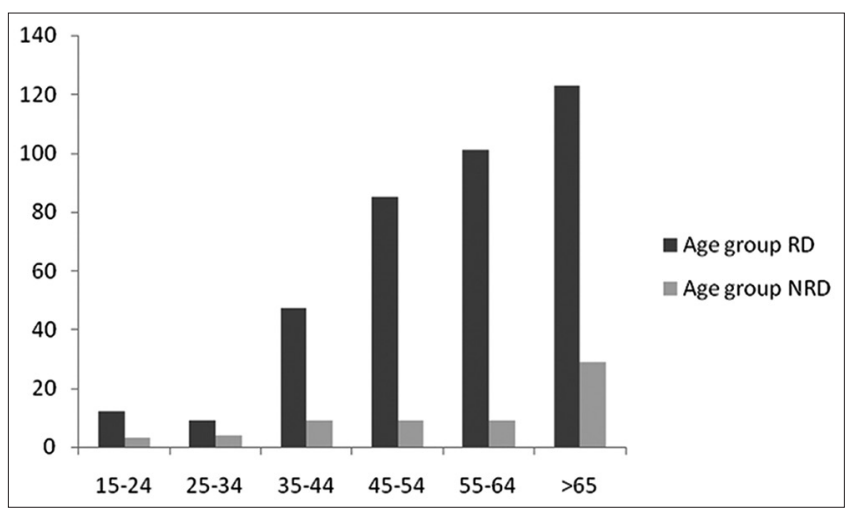

Fig. 2: Bar diagram death of diabetes patients with diabetesrelated and non-related complications age 68.7 years), CKD - 1.92\% (average age 61.2 years), coronary artery disease (CAD) - 1.57\% (average age 68.1 years), heart Failure - 1.83\% (average age 71.2 years). Death due to other diseases such as malignancy, seizures, burns, and accidents were $31.71 \%$. The diabetes patients died in less hospital stay period than nondiabetes patients, it was statistically significant as $\mathrm{p}=0.009$ (Table 5).

In those having DM, contributory factors for death were infections - 39.37\% (M-63\%, F-37\%) average age 59.8 years, CKD - 18.55\% (M-76\%, F-24\%) average age 63.9 years, CAD - 14.7\% (M-66\%, F-34\%) average age 63.58 years, stroke - 13.57\% (M-70\%, F-30\%) average age was 65.3 years, heart failure $-7.24 \%$ (M-76\%,

Table 1: Death of patients with or without diabetes according to age group

\begin{tabular}{llllllll}
\hline \multirow{2}{*}{$\begin{array}{l}\text { Age } \\
\text { group }\end{array}$} & \multicolumn{2}{l}{$\mathbf{D M}(\mathbf{N}=442)$} & & \multicolumn{3}{c}{ NDM (N=1148) } \\
\cline { 2 - 3 } \cline { 6 - 7 } & Male & Female & Total (\%) & & Male & Female & Total (\%) \\
\hline $15-24$ & 9 & 7 & $16(3.62)$ & & 36 & 25 & $61(5.31)$ \\
$25-34$ & 16 & 5 & $21(4.75)$ & & 64 & 46 & $110(9.58)$ \\
$35-44$ & 25 & 2 & $27(6.11)$ & 72 & 58 & $130(11.32)$ \\
$45-54$ & 53 & 36 & $89(20.14)$ & 96 & 79 & $175(15.24)$ \\
$55-64$ & 81 & 49 & $130(29.41)$ & 181 & 94 & $275(23.95)$ \\
$>65$ & 110 & 49 & $159(35.97)$ & 263 & 134 & $397(34.58)$ \\
Total & 294 & 148 & $442(100.00)$ & 712 & 436 & $1148(100.00)$ \\
\hline
\end{tabular}

DM: Diabetes mellitus, NDM: Nondiabetes mellitus

Table 2: Death with diabetes $(\mathrm{N}=442)$

\begin{tabular}{|c|c|c|c|c|c|c|}
\hline \multirow{2}{*}{$\begin{array}{l}\text { Age } \\
\text { group }\end{array}$} & \multicolumn{3}{|l|}{ DRD } & \multicolumn{3}{|c|}{ DNRD } \\
\hline & Male & Female & Total (\%) & Male & Female & Total (\%) \\
\hline $15-24$ & 7 & 5 & $12(2.71)$ & 1 & 2 & $3(0.68)$ \\
\hline $25-34$ & 5 & 4 & $9(2.04)$ & 2 & 2 & $4(0.90)$ \\
\hline $35-44$ & 32 & 15 & $47(10.63)$ & 6 & 3 & $9(2.04)$ \\
\hline $45-54$ & 56 & 29 & 85 (19.23) & 5 & 4 & $9(2.04)$ \\
\hline $55-64$ & 71 & 30 & $101(22.85)$ & 6 & 5 & $9(2.04)$ \\
\hline$>65$ & 83 & 40 & $123(27.83)$ & 22 & 7 & $29(6.56)$ \\
\hline Total & 254 & 123 & 377 (85.29) & 42 & 23 & 65 (14.71) \\
\hline
\end{tabular}

DRD: Diabetes related diseases, DNRD: Diabetes non-related diseases

Table 3: Death without diabetics $(\mathrm{N}=1148)$

\begin{tabular}{lllll}
\hline Disease & Sex & Number of death & $\begin{array}{l}\text { Average age at } \\
\text { death }\end{array}$ & p value \\
\hline CKD & M & 62 & $62.81 \pm 13.22$ & 0.29 \\
& F & 20 & $62.12552 \pm 14.28$ & \\
CAD & M & 42 & $64.38 \pm 14.17$ & 0.78 \\
& F & 23 & $63.23 \pm 14.15$ & \\
CVA & M & 36 & $63.73 \pm 10.21$ & 0.66 \\
& F & 24 & $62.52 \pm 12.83$ & \\
CHF & M & 18 & $68.03 \pm 15.5$ & 0.56 \\
& F & 14 & $66.39 \pm 17.6$ & \\
Infection & M & 117 & $61.92 \pm 12.24$ & 0.03 \\
& F & 53 & $61.23 \pm 13.45$ & \\
\hline
\end{tabular}

CKD: Chronic kidney disease, CAD: Coronary artery disease,

CVA: Cerebrovascular disease, CHF: Congestive heart failure

Table 4: Duration of hospital stay in diabetics with number of complication

\begin{tabular}{lll}
\hline Complication & $\begin{array}{l}\text { Number of } \\
\text { death (\%) }\end{array}$ & Hospital stay in days \\
\hline One complication & $79(17.87)$ & 25 \\
Two complication & $156(35.29)$ & 9 \\
Three or more complication & $207(46.83)$ & 4 \\
Total & $442(100)$ & - \\
\hline
\end{tabular}


F-24\%) average age 67.31 years, deaths not related to diabetes were $14.7 \%$. The percentage of overall deaths due to leading causes in diabetes and nondiabetes was compared with t-test and it was revealed highly significant ( $\mathrm{p}=0.01$, Table 5).

The death of DM due to CVA was classified into two groups, ischemic and hemorrhagic with respect to age group. It was revealed with t-test, i.e. there was no any significant between groups $(p=0.18)$. Whereas in total, irrespective of the age, with $\chi^{2}$ it was revealed that death due to hemorrhage was more as compared to ischemic ( $p=0.00001$, Table 6).

\section{DISCUSSION}

Mortality in diabetes is influenced by long-term vascular complications of diabetes, uncontrolled hyperglycemia; its metabolic sequelae, and/or treatment induced hypoglycemia. In most countries, mortality records under report diabetes as the primary, or underlying/contributory disease causing death [9,18-21]. Analyses of US death certificates (1999) indicate that the presence of diabetes is recorded in only $40-50 \%$ and is represented as a contributory cause of death in only $10-15 \%$ patients [22]. Factors contributing to increased mortality trends in developing countries include lack of awareness, poor drug compliance, inadequate secondary/tertiary hospital care facilities, unorganized referral system, poor patient transport service, affordability, and availability of effective drugs. Our study is an important addition to the scant literature in the mortality statistics of Indians with diabetes. Earlier data from other centers in India have shown that diabetes accounts for $2.5-10 \%$ of all deaths in hospital $[15,23,24]$. This is much higher with our observation of a $27.8 \%$ overall death rate in diabetes patients. It is higher as compare to other studies of India also. People in the eastern zone of the country have very poor drug compliance and they reach a secondary or tertiary care center only after landing up in

Table 5: Leading cause of death

\begin{tabular}{|c|c|c|c|c|c|c|}
\hline \multirow{2}{*}{$\begin{array}{l}\text { Disease } \\
\text { Diabetic related } \\
\text { disease }\end{array}$} & \multicolumn{3}{|c|}{ Diabetics (442) } & \multicolumn{3}{|c|}{ Non-diabetics (1148) } \\
\hline & NP & $\%$ & AHS & NP & $\%$ & AHS \\
\hline Infection & 174 & 39.37 & 6 & 395 & 34.41 & 11 \\
\hline CAD & 65 & 14.71 & 2 & 18 & 1.57 & 7 \\
\hline CKD & 82 & 18.55 & 7 & 22 & 1.92 & 20 \\
\hline CHF & 32 & 7.24 & 7 & 21 & 1.83 & 10 \\
\hline CVA & 60 & 13.57 & 2 & 19 & 1.66 & 18 \\
\hline DKA & 9 & 2.04 & 6 & - & - & - \\
\hline $\begin{array}{l}\text { Hyperosmolar } \\
\text { coma }\end{array}$ & 5 & 1.13 & 4 & - & & - \\
\hline $\begin{array}{l}\text { Hypoglycemia } \\
\text { Diabetic } \\
\text { non-related } \\
\text { disease }\end{array}$ & 4 & 0.90 & 2 & 12 & 1.05 & 19 \\
\hline $\begin{array}{l}\text { Gastrointestinal } \\
\text { bleeding }\end{array}$ & 9 & 2.04 & 14 & 98 & 8.54 & 12 \\
\hline Malignancy & 5 & 1.13 & 56 & 166 & 14.46 & 27 \\
\hline Others & 17 & 3.85 & 23 & 364 & 31.71 & 36 \\
\hline
\end{tabular}

NP: Number of patients, AHS: Average hospital stay, CAD: Coronary artery disease, CKD: Chronic kidney disease, CHF: Congestive heart failure,

CVA: Cerebrovascular disease, DKA: Diabetic ketoacidosis

Table 6: Comparison of type of CVA in fatal cases of DM

\begin{tabular}{lllll}
\hline S. No & Age & Ischemic & Hemorrhagic & p value \\
\hline 1 & $40-50$ & 2 & 5 & 0.1845 \\
2 & $51-60$ & 6 & 24 & \\
3 & $61-70$ & 7 & 10 & \\
4 & $71-80$ & 5 & 7 & \\
5 & $81-90$ & 2 & 2 & 0.00001 \\
Total & & 22 & 48 & \\
\hline
\end{tabular}

CVA: Cerebrovascular disease, DM: Diabetes mellitus complications [25]. Study from Netherlands reported less death with diabetes [26], while that from Canada is still lower [16].

We recorded the highest number of deaths in the age group of $>65$ years in patients with diabetes. Infection (39.37\%) accounted for the largest number of deaths in diabetes in our study. A high prevalence of infectionrelated mortality has been reported in other studies from India. Zargar et al. from Srinagar, Kashmir Valley reported $33.8 \%$ of all deaths related to infection [15]. In another Indian study, Das et al. from Orissa made a similar observation on infection related mortality (33.7\%) in diabetes [23]. The infection has also been noted as the leading cause of death in diabetic hospital inpatients from China and Brazil $[27,28]$. Of the infections, bronchopneumonia with pulmonary tuberculosis accounted for $19 \%$ of all diabetes deaths. Most of these patients were chronic bidi/cigarette smokers and had a history of repeated chest infection in preceding years. In Brunei, diabetes (67\%) was the most common predisposing factor for melloidosis, a serious pulmonary infection with high mortality [29]. In a population-based mortality study in the US, diabetes conferred 4 times increased mortality risk in the younger age group and almost twice mortality risk in the older age group from pneumonia and influenza [30]. Mortality and morbidity increased significantly among people with diabetes during epidemics of pneumonia and influenza $[31,32]$.

Individuals with diabetes carry a higher risk of severe chest infection through altered defense mechanisms from hyperglycemia, obesity and/or the effect of neuropathy and impaired tissue perfusion [33,34]. Diabetic foot and related sepsis were the second most common form of infection-related mortality. The habit of barefoot walking, working in fields in the country side and poor foot care predispose diabetics to recurrent trauma and infection. Poor socioeconomic status, lack of proper awareness of the disease and delayed presentation could be other important contributory factors. After infection, the second most common DRD was chronic kidney disease (CKD). The incidence rate was $18.55 \%$ in our study. CAD was the next common cause of death $14.71 \%$ in diabetes. Various clinical and epidemiological investigations from the West provide unequivocal evidence for cardiovascular $(60 \%)$ and cerebrovascular diseases $(15 \%)$ as the leading causes of mortality in diabetes [7-13]. Out of 9 patients presenting with DKA in our study, most of them died due to delayed admission and complicating infections. In other Indian studies, deaths from DKA ranged from 6.7 to $20 \%[14,35]$. In a study, it was revealed that uncontrolled diabetes for the first few years can cause acute cardiac and renal complications which are life-threatening [36]. Comparison of blood glucose at presenting and follow-up in association with education and counseling led to betterment of disease, outcome. Most of the diabetic hyperosmolar coma deaths occurred with infection. The death due to CVA in DM was more in hemorrhage as compared to ischemic $(p=0.00001)$. In another study, it was revealed that efforts are needed to increase the medication adherence of these patients so they can realize the full benefits of prescribed therapies [37]. This is an in-hospital study covering only those who died in a hospital. Hence, this does not reflect any scenario in the society at large population. A total of 1587 deaths in 4 years (average yearly adult deaths 397) against approx 42000 admissions per year are too low. This is probably due to very liberal policy of admission, this being a new upcoming hospital..

\section{CONCLUSION}

There has been an increase in diabetes-related mortality over the past decade. Unlike most of the western studies where CAD and stroke were the leading causes of death in diabetics, in our study, we found infection and CKD to be the leading causes. The overall increased mortality appears also attributable to the prevalence of cardiovascular diseases. Therefore, policy makers should pay more attentions to primary prevention of diabetes to reduce the incidence of death. While placing priority on the prevention of cardiovascular diseases, awareness must also be increased regarding any form of infection which should alarm the patient for medical attention to reduce the burden of diabetes- 
related deaths. It is also important to make the population aware of early screening for diabetes and ensure good glycemic control from the early stage to prevent/delay development of CKD.

\section{ACKNOWLEDGMENTS}

Authors are thankful to Prof. (Dr.) Gangadhar Sahoo, Dean, IMS and SUM Hospital, Prof. Manoj Ranjan Nayak, President, Siksha 'O' Anusandhan University for extending facilities in this research.

\section{REFERENCES}

1. Ramachandran A, Snehalatha C, Kapur A, Vijay V, Mohan V, Das AK, et al. High prevalence of diabetes and impaired glucose tolerance in India: National Urban Diabetes Survey. Diabetologia 2001;44(9):1094-101.

2. Pradeepa R, Deepa R, Mohan V. Epidemiology of diabetes in India - Current perspective and future projections. J Indian Med Assoc 2002;100(3):144-8.

3. World Health Organisation (WHO). Country and Regional da on Diabetes. Geneva: WHO; 2016.

4. Kapur A, Shishoo S, Ahuja MM, Sen V, Mankame K. Diabetes care in Indian/patients perceptions attitude and practices (DIPPAP-1) study. Int J Diabetes Dev 1997;17:2-12.

5. Rayappa PH, Raju KN, Kapur A, Bjork S, Sylvist C, Dilipkumar KM. Economic cost of diabetes care. Int J Diabetes Dev 1999;19:83-5.

6. World Development Report. Investigating in Health, World Development Indicators, World Bank. New York: Oxford University Press; 1993. p. 213-4.

7. Wingard LE, Cowie CC, Reiber G, Boyko E, Stern M, Bennet P. Heart disease and diabetes. In: Harris MI, editor. Diabetes in America. $2^{\text {nd }}$ ed. Washington, DC: NIH Publication; 1995. p. 429-48.

8. Geiss LS, Herman WH, Smith PJ, Harris MI, Cowie CC, Reiber G, et al., editors. Mortality in noninsulin dependent diabetes mellitus. In: Diabetes in America. $2^{\text {nd }}$ ed. Washington, DC: NIH Publication; 1995. p. 233-58.

9. Gu K, Cowie CC, Harris MI. Mortality in adults with or without diabetes in a national cohort of the US population, 1971-1993. Diabetes Care 1998;21:1138-45.

10. Palumbo PJ, Elvebaak LR, Chu CP, Conolly DC, Kirkland LT. Diabetes mellitus: Incidence, prevalence, survivorship and causes of death in Rochester. Diabetes 1976;25:566-73.

11. Pyorala K, Laakso M, Pyo"ra"la K, Teuscher A, editors. Diabetes in Epidemiological Perspective. Vol. 2. Edinburgh: Churchill Livingstone; 1983. p. 183-247.

12. Ochi JW, Melton LJ, Palumbo PJ, Chu CP. A population based study of diabetes mortality. Diabetes Care 1985;8:224-9.

13. Panzram G. Mortality and survival in Type 2 (Noninsulin-dependent) diabetes mellitus. Diabetologia 1987;30:123-31.

14. Sasaki A, Horiuchi N, Hasegawa K, Uehara M. Mortality and causes of death in Type 2 diabetic patients: A long term follow-up study in Osaka district, Japan. Diabetes Res Clin Pract 1989;7(1):33-40.

15. Zargar AH, Wani AI, Masoodi SR, Laway BA, Bashir MI. Mortality in diabetes mellitus--data from a developing region of the world. Diabetes Res Clin Pract 1999;43(1):67-74

16. Moulik PK, Mtonga R, Gill GV. Amputation and mortality in newonset diabetic foot ulcers stratified by etiology. Diabetes Care 2003;26(2):491-4.

17. World Health Organization. Annual of the International Statistical Classification of Diseases and Related Health Problems. 10 $0^{\text {th }}$ Revision. Geneva: World Health Organization; 1992.
18. Balkau B, Papoz L. Certification of cause of death in French diabetic patients. J Epidemiol Community Health 1992;46(1):63-5.

19. Sasaki A, Horiuchi N, Hasegawa K, Uehara M. The proportion of death certificates of diabetic patients that mentioned diabetes in Osaka district, Japan. Diabetes Res Clin Pract 1993;20:1021-4.

20. Anderrsen EM, Lea JA, Pecoraro RE, Koepsell TD, Hallstrom AP, Siscoviek DS. Under-reporting of diabetes on death certificates, King County, Washington. Am J Public Health 1993;83:1021-4.

21. Will JC, Vinicor F, Stevenson J. Recording of diabetes on death certificates. Has it improved? J Clin Epidemiol 2001;54:239-44.

22. National Diabetes Statistics: General Information and National Estimates on Diabetes in the United States. Deaths among People with Diabetes. Available from: http://www.niddk.nih.gov/health/diabetes/ pubs/dmstats/dmstats. [Last accessed on 2002 Oct 08].

23. Das S, Mishra RK, Jena BB, Misra KC, Sarangi B. Mortality events amongst non-insulin-dependent diabetes mellitus patients in Orissa. J Assoc Phys India 1991;39:519-20.

24. Ahuja MM. Causes of death amongst diabetics. Int J Diabetes Dev Ctries 1994;14:111-2.

25. Sagner M, Arena R, McNeil A, Brahmam GN, Hills AP, De Silva HJ, et al. Creating a pro-active health care system to combat chronic diseases in Sri Lanka: The central role of preventive medicine and healthy lifestyle behaviors: An official policy statement of the European society of preventive medicine. Expert Rev Cardiovasc Ther 2016;14(10):1107-17.

26. Baan CA, Feskens EJ. Disease burden of diabetes mellitus Type II in the Netherlands: Incidence, prevalence and mortality. Ned Tijdschr Geneeskd 2001;145(35):1681-5.

27. Tan MH, Maclean DR. Epidemiology of diabetes mellitus in Canada. Clin Invest Med 1995; 18:240-6.

28. Wei SY, Shin SJ, Chen JH, Chang JM, Sung MH, Lee YM, et al. Major causes of diabetic death at one hospital. Kaohsiung J Med Sci 1996;12(4):216-20.

29. Bisi H, Ruggeri GB, Longatto Filho A, Fernandes VS, De Camargo RY, Cravero NP. Study in necropsy material of "cause-specific mortality" in diabetics, in São Paulo-Brasil. Rev Paul Med 1993;111(1):299-304.

30. Nazarluqman H, Clee OS, Satyaswamy N, Da P. Meloidosis in Brunei - Epidemiological and clinical profile. Brunei Int Med J 1999;1:291-7.

31. Valdez R, Narayan KM, Geiss LS, Engelgau MM. Impact of diabetes mellitus on mortality associated with pneumonia and influenza among non-Hispanic black and white US adults. Am J Public Health 1999;89(11):1715-21.

32. Bouter KP, Diepersloot RJ, van Romunde LK, Uitslager R, Masurel N, Hoekstra JB, et al. Effect of epidemic influenza on ketoacidosis, pneumonia and death in diabetes mellitus: A hospital register survey of 1976-1979 in The Netherlands. Diabetes Res Clin Pract 1991;12(1):61-8

33. Geiss LS, Thompson TJ. Are persons with diabetes more likely to die from pneumonia and influenza. Diabetes 1995;44:124A.

34. Koziel H, Koziel MJ. Pulmonary complications of diabetes mellitus. Pneumonia. Infect Dis Clin North Am 1995;9(1):65-96.

35. Dash RJ, Dash S, Virdi JS. Neutrophil function in diabetes: Effect of glycemic control. Presented in the $17^{\text {th }}$ IDF Congress (Abstract No. P1436), Mexico City, November; 2000

36. Mounika S, Keerthy V, Ramadasu P, Sanakayala BU, Chaitanya L. Prevalence of acute cardiac and renal complications in poorly controlled diabetics and role of clinical pharmacist in modifying disease outcome in a tertiary care hospital. Int J Pharm Pharm Sci 2015;7(6):92-6.

37. Manjusha S, Madhu P, Atmatam P, Amit M, Ronak S. Medication adherence to antidiabetic therapy in patients with Type 2 diabetes mellitus. Int J Pharm Pharm Sci 2014;6(2):564-70. 